\title{
Morpho-physiological effect of selenium on salinity-stressed wheat (Triticum aestivum L.)
}

\author{
James Oludare Agbolade, ${ }^{1,2}$ Oyinade David, ${ }^{1}$ Abiodun Ajiboye, ${ }^{1}$ Joseph Kioko, ${ }^{2}$ Okanlawon Jolayemi, ${ }^{3}$ \\ Idowu Olawuni, ${ }^{4}$ Mercy Ojo, ${ }^{1}$ Gbenga Akomolafe, ${ }^{5}$ Modinat Adekoya, ${ }^{1}$ Ronke Komolafe ${ }^{1}$ \\ ${ }^{1}$ Department of Plant Science and Biotechnology, Federal University Oye-Ekiti, Ekiti State, Nigeria; ${ }^{2}$ Department of \\ Biodiversity and Conservation, Cape Peninsula University of Technology, Cape Town, South Africa; ${ }^{3}$ Department of \\ Plant Breeding, Swedish University of Agricultural Sciences, Alnarp, Sweden; ${ }^{4}$ Department of Biochemistry, Obafemi \\ Awolowo University, Ile-Ife, Osun State, Nigeria; ${ }^{5}$ Department of Botany, Federal University Lafia, Nasarawa State, \\ Nigeria
}

\begin{abstract}
Wheat (Triticum aestivum) is an important grains plant that can sustain food security and holds high nutritional values to the benefit of mankind. Activities of salinity in arid and semi-arid region have drastically reduced the production of wheat grains. Selenium $(\mathrm{Se})$ is a micronutrient required by plants in small concentration to aid their growth. This study was aimed at identifying impact of Se on salinity-stressed wheat plants. Wheat seeds were soaked for eight hours in $0,50,100$ and $150 \mathrm{mg} / \mathrm{L}$ Selenite concentrations and five sterilize-treated seeds were sown in $5 \mathrm{~kg}$ quantity of soil. This was subjected to 0,100 and $200 \mathrm{mM}$ of Sodium chloride $(\mathrm{NaCl})$ concentration, respectively. The study revealed that $\mathrm{Se}$ increased production/expression of superoxide dismutase and catalase enzymes under salinity stress, thus growth
\end{abstract}

Correspondence: James Oludare Agbolade, Department of Plant Science and Biotechnology, Federal University Oye-Ekiti, Ekiti State; P.O. Box 1475, Ile-Ife, Osun State, Nigeria.

E-mail: oludareagbolade@gmail.com

Key words: Wheat; Salinity; Selenite; Growth; Chlorophyll contents.

Contributions: JO and OD developed the original idea and the protocol, drafted and analyzed data, wrote the manuscript; MA, RK, OJ, IO, GA and $\mathrm{MO}$ provided experimental materials, equipment and manuscript correction; AA and JK revised critically for important intellectual and final approval of the version to be published.

Conflict of interest: the authors declare no potential conflict of interest.

Funding: none.

Received for publication: 19 June 2018.

Revision received: 19 December 2018.

Accepted for publication: 7 January 2019.

CC Copyright J.O. Agbolade et al., 2019

Licensee PAGEPress, Italy

Journal of Biological Research 2019; $92: 7650$

doi:10.4081/jbr.2019.7650

This article is distributed under the terms of the Creative Commons Attribution Noncommercial License (by-nc 4.0) which permits any noncommercial use, distribution, and reproduction in any medium, provided the original author(s) and source are credited. of wheat plants was improved. Although the effects of Se on the wheat plants were concentration-based, nevertheless low lipid peroxidation and plant growth at $150 \mathrm{mg} / \mathrm{L}$ of Se were observed. Toxicity of Se to wheat plant could occur when there is no salinity stress. Therefore, farmers are encouraged to prime wheat seeds with $150 \mathrm{mg} / \mathrm{L}$ Se when cultivating saline soils.

\section{Introduction}

Wheat (Triticum aestivum L.) is an essential staple food crop, nourishing more than one-third of the world's population ${ }^{1,2}$ and contributing more calories (327 calories per 100 grams) and proteins to the world's diet than any other cereal crop. ${ }^{3}$ It consists of about $71 \%$ carbohydrates, $13 \%$ protein, $13 \%$ water and $1.5 \%$ fat. Wheat is also a great source of fiber, vitamin B and many minerals. ${ }^{4}$ Wheat has a widespread geographic distribution, acceptance, stability, and versatility; therefore it is suitable for supplying micronutrients to mankind (USAID). However, its nutritional compositions and crop yield are considerably influenced by environmental conditions, resulting from global climate change. ${ }^{1}$ The global wheat production between the years 2000 and 2017 ranges from 582-750.7 million Metric Tons (MT) while the 2017/18 cropping season, gave an average of 759.75 million MT. ${ }^{3}$ China is the highest producer of wheat worldwide followed by India. It is a popular cash crop growing in Nigeria, however, domestic wheat production is very low, amounting to 90,000 tons, while consumption/demand is much higher; over 4 million tons of wheat is needed to satisfy the national demand. ${ }^{2}$

Salinity is one of the major abiotic stresses which adversely affect the seed germination. ${ }^{4,5}$ Nearly half of the irrigated land and $20 \%$ of the world's cultivated land are currently affected by salinity, ${ }^{6}$ due to excessive irrigation and poor soil drainage. ${ }^{7}$ Agricultural productivity is severely affected by soil salinity and the damaging effect of salt accumulation in agricultural soils has become an important environmental concern. ${ }^{8}$ The deleterious effect of salinity on plant growth is attributed to the decreased osmotic potential of growing medium, specific ion toxicity, and nutrient ions deficiency. ${ }^{5}$ Salinity affects many morphological, physiological and biochemical processes, including seed germination, plant growth, and water as well as nutrient uptake. ${ }^{5}$ Plant tolerance to salinity depends on growth stages and species of the plant. ${ }^{9}$ Crop plants are more severally affected by salinity at early stage and particularly barley, wheat and corn are more sensitive 
during seed germination. ${ }^{10}$ Many researchers have reported that several plants are sensitive to high salinity during germination and the seedling stage. 5,9

Selenium (Se) is an essential nutrient for maintenance of animal and human health, but it is required in low concentrations. ${ }^{11}$ However, its role in plant physiology is still unclear. ${ }^{11,12}$ Indications exist about the beneficial effects of Se on plant growth at low concentrations. Se is known to play a crucial role in antioxidation in biological organisms by stimulating the activity of glutathione peroxidase, which is capable of scavenging hydrogen peroxides. ${ }^{11}$

Seed priming is a type of seed enhancement technology. It is a controlled hydration technique, which is very effective and an indispensable approach to enhance emergence, seedling vigor and stress tolerance of many field crops including wheat. ${ }^{12-14}$

Priming offers an effective means for counteracting sub-optimal temperature-induced oxidative injury and raising seed performance in many crop species. ${ }^{15,16}$ Recent evidence has shown that priming enhances the activities of several antioxidative enzymes and increases the level of a variety of antioxidants (e.g. glutathione and ascorbate). ${ }^{15}$ Plants raised from primed seeds show vigorous start and greater stress tolerance primarily due to more efficient energy metabolism, osmotic adjustment, enlarged embryo, enhanced enzyme activation, and quick cellular defense responses. ${ }^{13}$ It has also further been established that seed priming has been proved as a promising approach in modern stress management as it protects plants against pathogens and abiotic stresses without affecting fitness. ${ }^{13}$ Seed priming was also found by $\mathrm{Xu}$ et $a l .{ }^{17}$ to improve tolerance to chilling temperature in tobacco during seed germination and seedling growth by the activation of antioxidant system in the plant tissues. Seed priming-induced enhancements in antioxidative defense system of rice seedlings have been well-reported. ${ }^{18,19}$ Rajpar et al. ${ }^{20}$ also reported the effect of seed priming on growth and yield of wheat (Triticum aestivum L.) under non-saline conditions and Summiya et al. ${ }^{21}$ reported morpho-physiological assessment of wheat genotypes for drought stress tolerance but only at seedling stage. Therefore, this current study was undertaken to determine the effects of different salt concentrations, generally on growth and physiology of Se-primed and unprimed wheats. Seeds were primed with a variety of sodium selenite solutions and the changes in the level of antioxidants examined, as a function of Se levels.

\section{Materials and Methods}

\section{Study area}

The experiment was carried out at the Teaching and Research Farm of the Department of Plant Science and Biotechnology, Federal University, Oye - Ekiti, Ekiti State, Nigeria. The farm is located within the coordinates $7.780000^{\circ} \mathrm{N}, 5.321800^{\circ} \mathrm{E}$ with an elevation of $270 \mathrm{~m}$ above the sea level of tropical forest. The average annual rainfall varies from $1200 \mathrm{~mm}$ to $1400 \mathrm{~mm}$ with temperature ranging from $21^{\circ} \mathrm{C}$ to $28^{\circ} \mathrm{C}$ with high humidity. The soils are rich in humus and minerals, laterites, clay and sand which support tropical forest vegetation. The region of Ekiti (Southwest, Nigeria) has semi-deciduous forests or woodland and savannah woodland.

\section{Seeds collection and cultivation}

Wheat's seeds were obtained from the National Centre for Genetic Resources and Biotechnology (NACGRAB), Ibadan,
Oyo-State, Nigeria. The seeds were surface sterilized with $15 \%$ sodium hypochlorite and pre-treated with $0,50,100$ and 150 $\mathrm{mg} / \mathrm{L}$ Selenites concentrations for eight hours to represent Se, Se50, Se100 and Se150, respectively. ${ }^{22}$ The seeds were planted in plastic bucket spaced 1metre apart and watered for four weeks in the screen house of the Department of Plant Science and Biotechnology, Federal University, Oye-Ekiti, Ekiti State, Nigeria. Initially, several seeds were planted per polythene bag and later thinned to five plants per bag. Four weeks after planting, plants were subjected to varying concentrations of salinity stress of 0,100 and $200 \mathrm{mM}$ Sodium chloride $(\mathrm{NaCl})$ representing at S, S100 and S200 respectively. ${ }^{23}$ Plants were irrigated six times with the varying concentrations of $\mathrm{NaCl}$ and characters such as plant height, number of leaves and number of tillers per plant were measured. Fresh leaves were collected for biochemical analysis. Three replicates of the polythene bag were prepared and the screen house was kept clean throughout the period of the study.

\section{Chlorophyll determination}

Chlorophyll contents were extracted from the leaves, the extraction of leaf pigments was performed with $100 \%$ acetone, ${ }^{24}$ while absorbance was measured at 470, 662 and $645 \mathrm{~nm}$ using spectrophotometer (UV - Visible Spectrophotometer Model LT290, Labtronics, India). The formula below was used in the calculation of chlorophyll $\mathrm{a}, \mathrm{b}$ and total carotene contents in $\mathrm{mg} / \mathrm{mL}$.

$$
\text { Acetone }
$$

Chlorophyll a $\left(\mathrm{C}_{\mathrm{a}}\right)=11.75 \mathrm{~A}_{662}-2.350 \mathrm{~A}_{645}$

Chlorophyll b $\left(\mathrm{C}_{\mathrm{b}}\right)=18.61 \mathrm{~A}_{645}-3.960 \mathrm{~A}_{662}$

Total Carotene $(\mathrm{Cx}+\mathrm{c})=1000 \mathrm{~A}_{470}-2.270 \mathrm{C}_{\mathrm{a}}-81.4 \mathrm{C}_{\mathrm{b}} / 227$

\section{Antioxidant enzymes determination}

Leaf samples were homogenized in cold $50 \mathrm{mM}$ Sodium phosphate buffer ( $\mathrm{pH}$ 7.8) for the enzyme extractions.

Ascorbate peroxidase (APX) activity was measured according to the methods of Chibueze. ${ }^{25}$ The reaction mixture contained 50 $\mathrm{mM}$ potassium phosphate buffer $(\mathrm{pH} 7.0), 0.5 \mathrm{mM}$ ascorbic acid, $0.1 \mathrm{mM}$ hydrogen peroxide, and $0.1 \mathrm{~L}$ of enzyme extract in a total volume of $1 \mathrm{~mL}$. Absorbance was measured at $290 \mathrm{~nm}$ using spectrophometer.

Catalase (CAT) activity was measured according the method of Aebi. ${ }^{26}$ Fifty microliter $(50 \mu \mathrm{L})$ of the extract was added to a cuvette containing $450 \mu \mathrm{L}$ of phosphate buffer $(0.1 \mathrm{M}, \mathrm{pH} 7.4)$ and $500 \mu \mathrm{L}$ of $20 \mathrm{mM} \mathrm{H}_{2} \mathrm{O}_{2}$. Catalase activity was measured at $240 \mathrm{~nm}$ for 1 min using spectrophotometer.

Superoxide dismutase (SOD) activity was measured according to the method described by McCord and Fridovich. ${ }^{27}$ To $50 \mu \mathrm{L}$ of the plant extract, $75 \mathrm{mM}$ of Tris- $\mathrm{HCl}$ buffer (pH 8.2), $30 \mathrm{mM}$ EDTA and $2 \mathrm{mM}$ of pyrogallol were added. An increase in absorbance was recorded at $420 \mathrm{~nm}$ for 3 mins by spectrophotometer.

\section{Lipid peroxidation determination}

Total amount of lipid peroxidation products present in the plant samples was estimated by the thiobarbituric acid (TBA) method which measures the malondialdehyde (MDA) reactive products according to the method of Smerg and Sharma. ${ }^{28}$ To $0.5 \mathrm{~mL}$ of samples was added $0.5 \mathrm{~mL}$ of phosphate buffer $(0.1 \mathrm{M}, \mathrm{pH} 8.0)$ and $0.5 \mathrm{~mL}$ of $24 \% \mathrm{TCA}$. The resulting mixture was incubated at room temperature for 10 minutes, followed by centrifugation at 2000 rpm for 20 min. To $1 \mathrm{~mL}$ of supernatant was added $0.25 \mathrm{~mL}$ of $0.33 \%$ TBA in $20 \%$ acetic acid and the resulting mixture was boiled at $95^{\circ} \mathrm{C}$ for 1 hour. The resulting pink colour product was 
cooled down and absorbance was read at $532 \mathrm{~nm}$. Extinction coefficient of MDA, (ع) $532=1.53 \times 105 \mathrm{M}^{-1} \mathrm{~cm}^{-1}$.

\section{Results}

\section{Effects on growth}

Results from growth of wheat primed with different concentrations of Se under different induced-salinity stress indicated decrease in plant height as the salt concentration increases in Se (control) and Se 50 (Figure 1). When compared with Se control, Se increased the plant height under different levels of salinity as well as the number of leaves and tillers. Plants at S100Se150 (100 mM salt and 150 $\mathrm{mg} / \mathrm{L} \mathrm{Se}$ ) had the highest number of leaves and tillers. Number of tillers at Se and Se50 decreased as the salinity increased.

\section{Effects on antioxidants enzymes}

Figure 2 shows that SOD enzymes increased significantly as the level of Se increased and at Se (control) and Se50, SOD enzymes decreased as the level of salinity increased. Whereas at
Se100 and Se150, the SOD enzymes increased as the salt concentration increased and plants with Se 150 had the highest SOD activities. Activities of CAT were high at S100Se100 (100 mM salt and $100 \mathrm{mg} / \mathrm{L} \mathrm{Se}$ ). APX and CAT enzymes deceased with no significance as the salinity level increased in Se (control). Activities of APX were high in plants without salt S (control) across all the levels of Se used. Plants under SSe50 (no salt and $50 \mathrm{mg} / \mathrm{L} \mathrm{Se}$ ) had a significant high APX which is the major scavenger of hydrogen peroxides (Figure 2).

\section{Effects on lipid peroxidation}

As shown in Figure 3, low lipid peroxidation was observed in $\mathrm{Se}$ (control) at all levels of salinity stress and its peak was observed at $\mathrm{SSe} 50$ (no salt and $50 \mathrm{mg} / \mathrm{L} \mathrm{Se}$ ). High toxic level was observed at $50 \mathrm{mg} / \mathrm{L} \mathrm{Se}$ without salt. When salinity stress was introduced with an increase in concentration of Se, low lipid peroxidation was observed at S100Se50 (100mM salt and $50 \mathrm{mg} / \mathrm{L} \mathrm{Se})$ and $\mathrm{S} 200 \mathrm{Se} 50$ (200 $\mathrm{mM}$ salt and $50 \mathrm{mg} / \mathrm{L} \mathrm{Se})$.

\section{Effects on chlorophyll content}

Figure 4 shows that plants at Se control and Se50 showed a
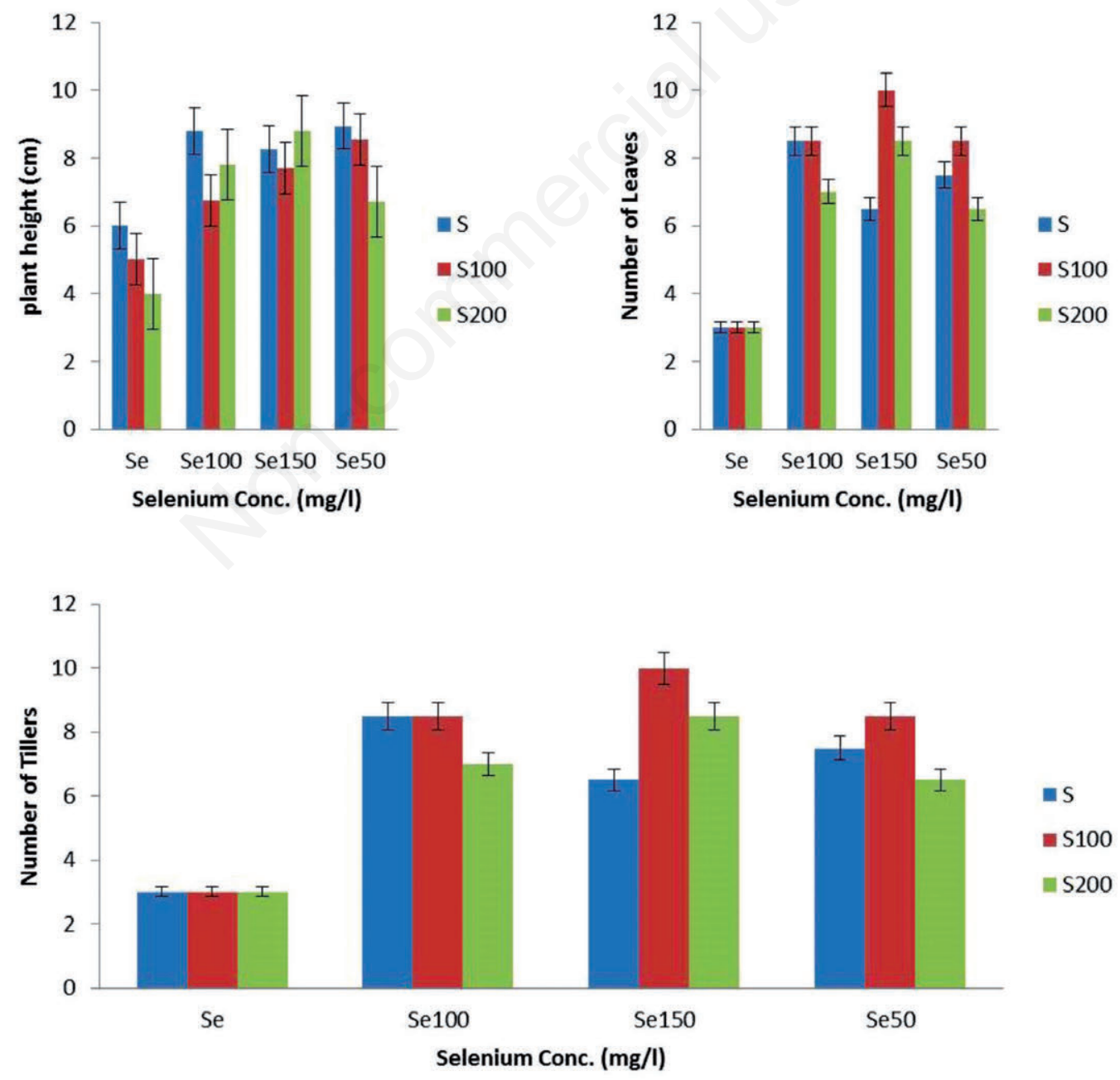

Figure 1. Bar charts showing the growth of wheat primed with different selenium concentrations under different induced-salinity stresses. 
decrease in chlorophyll a, b, total chlorophyll and total carotenoid as the salinity level increased. Wheat seeds primed with SSe50 Se (no salt and $50 \mathrm{mg} / \mathrm{L} \mathrm{Se}$ ) also had the highest chlorophyll a, b, total chlorophyll and total carotenoid.

\section{Discussion}

Decrease in plant height was recorded as the salt concentration increases in $\mathrm{Se}$ (control) and $\mathrm{Se} 50$. The lower productivity in most of the cases is attributed to various abiotic stresses. The salinity impact has threefold effect as follows: they reduce water potential and cause ion imbalance or disturbances in ion homeostasis and toxicity; this altered water status leads to initial growth reduction and limitation of plant productivity. The detrimental effect is observed as death of plants or decrease in productivity. ${ }^{23}$ Therefore, increase in concentration of Se helps to boost the growth of wheat under drought stress. The number of tillers at Se and Se50, that decreased as the salinity increased, is indicative of the presence of salt in the soil solution which always reduces the ability of the plant to take up water and this leads to reductions in the growth rate. This is referred to as the osmotic or water-deficit effect of salinity. Secondly, if excessive amounts of salt enter the plant in the transpiration stream, there will be injury to cells in the transpiring leaves and this may cause further reductions in growth. This is called the salt specific or ion-excess effect of salinity. ${ }^{29}$

The significant increase in the level of SOD enzymes as the level of Se increased and the decrease as the level of salinity increased at $\mathrm{Se}$ (control) and $\mathrm{Se} 50$ could result in an increased risk of oxidative damage in salt-treated plants that leads to the formation of reactive oxygen species. The increase in SOD enzymes activities at $\mathrm{Se} 100$ and $\mathrm{Se} 150$ as the salt concentration increases accounted for the reasons we had high growth of wheat at Se150 concentration because SOD helps to dismutase the superoxide radicals produced during stress. Similarly, Priming with 15-60 $\mu \mathrm{mol} / \mathrm{L}$ Se favored rice emergence and seedling growth. ${ }^{30}$ Wheat cultivar Kohistan-97 was found to be more responsive to Selinite treatments as one hour priming at $100 \mu \mathrm{M}$ significantly increased its total biomass by $43 \%$ as compared to control treatments. ${ }^{31}$ Degradation of these superoxides ultimately helps in removal of other radicals that can also eventually be produced from superoxides radicals such as hydroxyl and hydrogen peroxide.

However, the fact that activities of CAT were high at S100Se100 (100 $\mathrm{mM}$ salt and $100 \mathrm{mg} / \mathrm{L} \mathrm{Se}$ ), the decreased activities of APX and CAT enzymes with no significance as the salinity level increased in
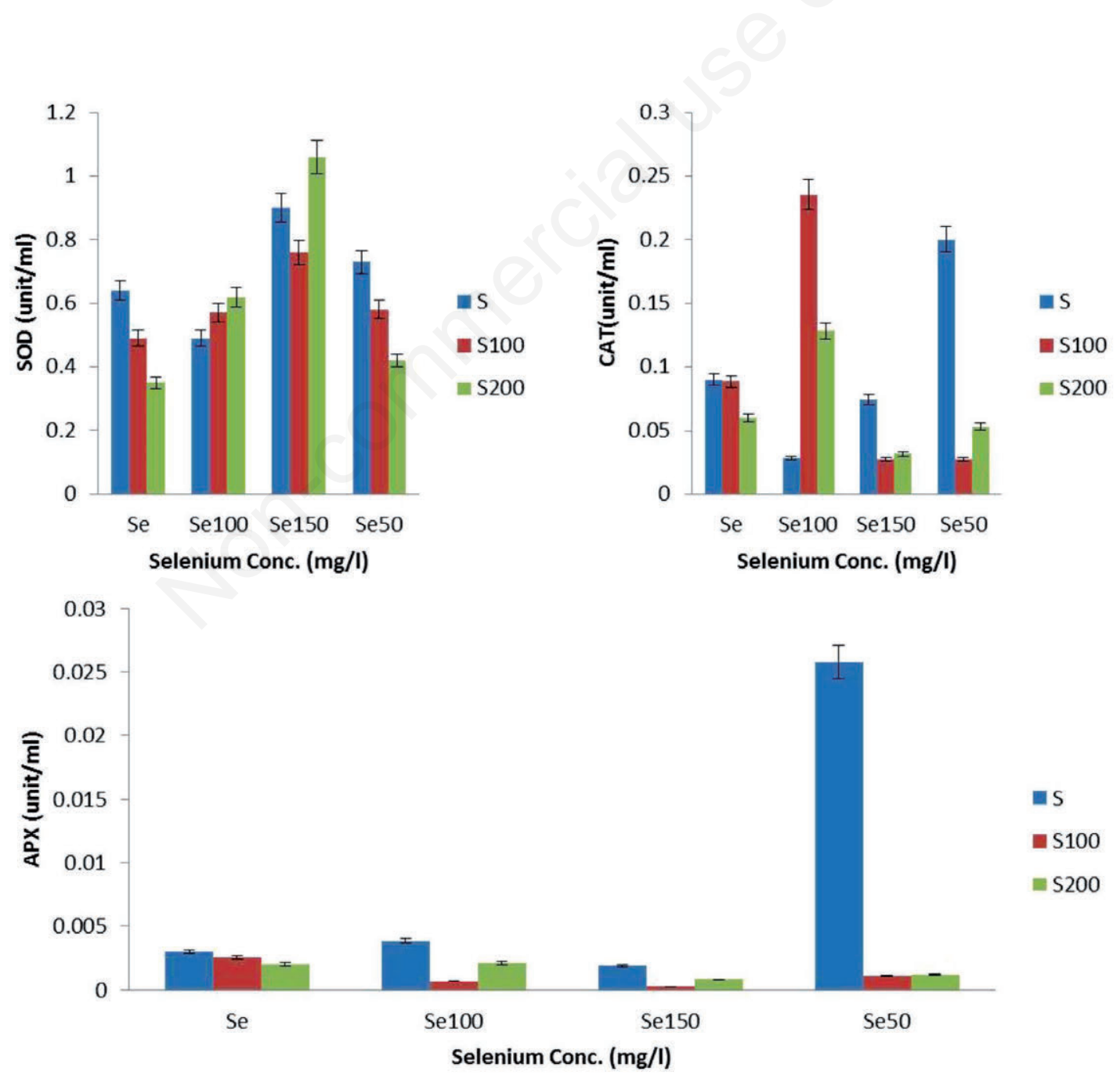

Figure 2. Bar charts showing actions of antioxidants enzymes of selenium primed wheat under different salinity stresses. SOD, superoxide peroxidase; CAT, catalase; APX, ascorbic peroxidase. 
Se (control) and high actions of APX in plants without salt S (control) across all the levels of Se used are logical implications that Se stabilizes and promotes activities of SOD, APX and CAT in seed primed wheat. This is in agreement with de los Santos-Vázquez et $a l .{ }^{32}$ where Se significantly modified melon growth. The application of Se by irrigation and leaf spraying in seedlings has also found to significantly improve the antioxidant status. ${ }^{33}$ Selenite also generally enhanced CAT, Guaiacol peroxidase GPOX, and Glutathione GSH-Px activities under oxidation stress. ${ }^{33}$

Low lipid peroxidation observed in Se (control) in all levels of salinity stress was indicative that all the concentrations of salinity used did not have a significant effect on lipids. High toxic level was observed at $50 \mathrm{mg} / \mathrm{L} \mathrm{Se}$ without salt, thus suggested destruction of lipid at this concentration of Se without the plant undergoing stress which resulted to low growth of wheat. When salinity stress was introduced with an increase in concentration of Se, low lipid peroxidation was observed at S100Se50 (100 mM salt and 50 $\mathrm{mg} / \mathrm{L} \mathrm{Se}$ ) and S200Se50 (200 mM salt and $50 \mathrm{mg} / \mathrm{L} \mathrm{Se})$. This resulted to an interaction between an increase in Se and salt stress in reduction of lipid peroxidation. Therefore, Se becomes a toxin to lipids of wheat when there is salinity stress. SSe 50 had the highest APX, chlorophylls a, b and total carotenoid with high level of lipid peroxidation.
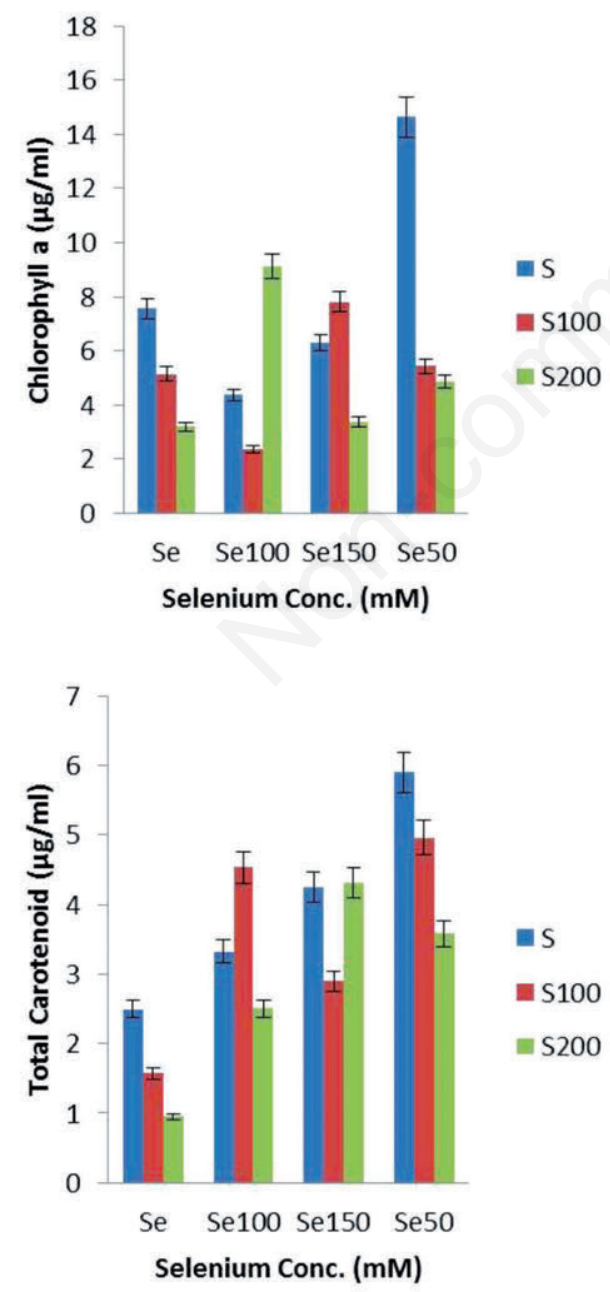

Chlorophyll a, b, total chlorophyll and total carotenoid were decreased as the salinity level (Se control and Se50) increased. Wheat seeds primed with SSe $50 \mathrm{Se}$ (no salt and $50 \mathrm{mg} / \mathrm{L} \mathrm{Se}$ ) had the highest chlorophylls a, b, total chlorophyll and total carotenoid thus, corroborate the research outcome where rice seedlings

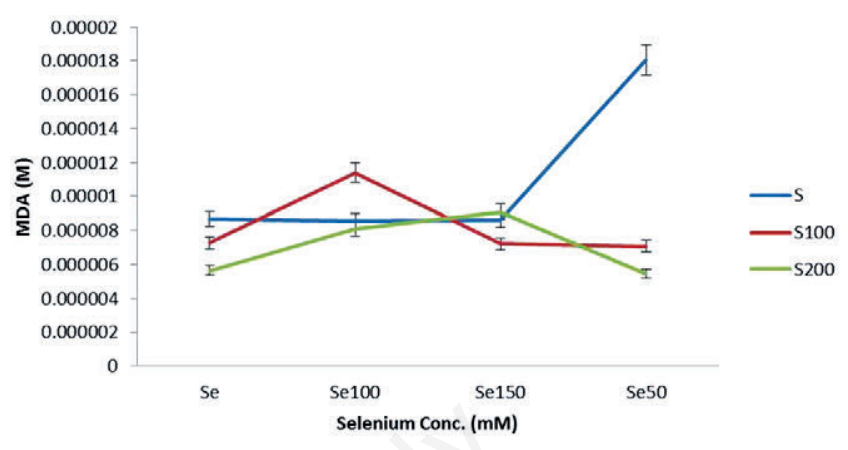

Figure 3. Graph showing lipid peroxidation in seed primed wheat under different level of salinity stress. MDA, malondialdehyde.

Figure 4. Bar charts showing chlorophyll contents of seed primed wheat under different level of salinity stresses. 
derived from Se-primed seeds exhibited more chlorophylls. ${ }^{18}$ While wheat treated with S100Se100 (100 mM Salt and $100 \mathrm{mg} / \mathrm{L}$ $\mathrm{Se}$ ) had low chlorophylls a and b, chlorophylls a and b were significantly higher at Se100 than in S200 and then in other levels of salinity stress.

\section{Conclusions}

Effect of Se on salinity stressed wheat is concentration based. Se boosted the activities of antioxidant enzymes and chlorophyll contents in salinity stressed wheat plants. During salinity stress, high plant growth such as plant height, number of leaves and tillers, SOD and low lipid peroxidation were found when $150 \mathrm{mg} / \mathrm{L}$ of Se were fortified. Furthermore, seeds primed with $50 \mathrm{mg} / \mathrm{L}$ of Se also showed high level of APX, chlorophylls a and $b$ and total carotenoid but destruction of lipid was observed at this concentration. Therefore, $150 \mathrm{mg} / \mathrm{L}$ of Se is hereby suggested when priming wheat seeds in salinity environment.

\section{References}

1. Adams ML, Lombi E, Zhao FJ, McGrath SP. Evidence of low selenium concentrations in UK bread-making wheat grain. J Sci Food Agric 2002;82:1160-5.

2. Enghiad A, Ufer D, Countryman AM, Thilmany DD. An overview of global wheat market fundamentals in an era of climate concerns. Int J Agron 2017;3931897.

3. Yu S, Tian L. Breeding major cereal grains through the lens of nutrition sensitivity. Mol Plant 2018;11:23-30.

4. Kochak-Zadeh A, Mousavi SH, Eshraghi-Nejad M. The effect of salinity stress on germination and seedling growth of native and breeded varieties of wheat. J Novel Appl Sci 2013;2:703-9.

5. Ibrahim EA. Seed priming to alleviate salinity stress in germinating seeds. J Plant Physiol 2016;192:38-46.

6. Goldani M, Latifi N. Effect of salinity on germination and seedling growth of three cultivars of wheat. J Agr Sci Nat Res 2006;2:47-52.

7. Asgharipour MR, Rafiei M. Effect of salinity on germination and seedling growth of lentils. Austr J Basic Appl Sci 2011;5: 2002-4.

8. Jaleel CA, Sankar B, Sridharan R, Panneereselvam R. Soil salinity alters growth, chlorophyll content, and secondary metabolite accumulation in Catharanthus roseus. Turk J Biol 2008;32:79-83

9. Machado RMA, Serralheiro RP. Soil salinity: effect on vegetable crop growth management practices to prevent and mitigate soil salinization. Horticulturae 2017;3:30.

10. Begum F, Ahmed IM, Nessa A, Sultana W. The effect of salinity on seed quality of wheat. J Bangl Agr Uni 2010;8:19-22.

11. Gupta M, Gupta S. An overview of selenium uptake, metabolism and toxicity in plants. Front Plant Sci 2016;7:2074.

12. Hajiboland R, Amjad L. Does antioxidant capacity of leaves play a role in growth response to selenium at different sulfur nutritional status? Plant Soil Environ 2007;53:207-15.

13. Jisha KC, Vijayakumari K, Puthur TJ. Seed priming for abiotic stress tolerance: an overview. Acta Physiol Plant 2013;35: 1381-96.

14. Paparella S, Araújo SS, Rossi G, et al. Seed priming: state of the art and new perspectives. Plant Cell Rep 2015;34:1281-93.
15. Nawaz J, Hussain M, Jabbar A, et al. Seed priming: a technique. IJACS 2013;6:1373-81.

16. Min Y. Seed priming stimulate germination and early seedling growth of Chinese cabbage under drought resistance. South Afr J Bot 2015;99:88-92.

17. Xu S, Hu J, Li Y, et al. Chilling tolerance in Nicotiana tabacum induced by seed priming with putrescine. Plant Growth Regul 2011;63:279-90.

18. Zhen M, Tao Y, Hussain S, et al. Seed priming in dry directseeded rice: consequences for emergence, seedling growth and associated metabolic events under drought stress. Plant Growth Regul 2015;78:167-78.

19. Hussain S, Khan F, Cao W, et al. Seed priming alters the production and detoxification of reactive oxygen intermediates in rice seedlings grown under sub-optimal temperature and nutrient supply. Front Plant Sci 2016;7:1-13.

20. Rajpar I, Khanif YM, Memon AA. Effect of seed priming on growth and yield of wheat (Triticum aestivum L.) under nonsaline conditions. Int J Agr Res 2006;1:259-64.

21. Summiya F, Mujtaba SM, Khan MA, Wajid M. Morpho-physiological assessment of wheat (Triticum aestivum L.) genotypes for drought stress tolerance at seedling stage. Pak J Bot 2017;49:445-52.

22. Yao X, Chu J, Liang L, et al. Selenium improves recovery of wheat seedlings at rewatering after drought stress. Russ J Plant Physiol 2012;59:701-7.

23. Parihar P, Singh S, Singh S, et al. Effect of salinity stress on plants and its tolerance strategies: a review. Environ Sci Pollut Res Int 2015;22:4056-75.

24. Wellburn AR. The spectral determination of chlorophylls a and b, as well as total carotenoids, using various solvents with spectrophotometers of different resolution. J Plant Physiol 1994;144:307-13.

25. Chibueze N. Changes in the activity os ascorbate peroxidase under anaerobiosis in cocoyam (Colocasia esculenta). Pak J Biol Sci 2014;17:138-40.

26. Aebi HB. Catalase in vitro. Methods Enzymol 1984;105:121-6.

27. McCord JM, Fridovich I. Superoxide dismutase. An enzymic function for erythrocuprein (hemocuprein). J Biol Chem1969; 244:6049-55.

28. Smerg J, Sharma M. Possible mechanism of Murraya koenigii and Cinnamomum tamala with reference to antioxidant activity. Int J Pharm Sci Drug Res 2011;33:260-4.

29. Hemantaranjan EA. Advances in plant physiology. Jodhpur, India: Scientific Publisher; 2012. pp 389-414.

30. Khaliq AF, Aslam A, Matloob S, et al. Seed priming with selenium: consequences for emergence, seedling growth, and biochemical attributes of rice. Biol Trace Elem Res 2015;166: 236-44.

31. Nawaz F, Ashraf MY, Ahmad R, Waraich EA. Selenium (Se) seed priming induced growth and biochemical changes in wheat under water deficit conditions. Biol Trace Elem Res 2013;151:284-93.

32. de los Santos-Vázquez ME, Benavides-Mendoza A, RuizTorres NA, et al. Sodium selenite treatment of vegetable seeds and seedlings and the effect on antioxidant status. Emir J Food Agr 2016;28:589-93.

33. Mroczek-Zdyrska M, Strubinska J, Hanaka A. Selenium improves physiological parameters and alleviates oxidative stress in shoots of lead-exposed Vicia faba L. minor plants grown under phosphorus-deficient conditions. J Plant Growth Regul 2017;36:186-99. 